\title{
1. Introduction to the Handbook on Tourism and Social Media
}

\author{
Rahul Pratap Singh Kaurav and Dogan Gursoy
}

The rapid development of information technology during the last two decades and the resulting social media development have significantly influenced and reshaped tourism, hospitality and events domains. Even though most of the social media platforms have emerged during the last decade, those social media platforms have become critical mediums for information dissemination and gathering for both consumers and destination marketers and managers. Since consumers heavily use social media and peer-to-peer information sharing platforms as critical sources of information during their decision-making processes, it is not surprising to see that those social media platforms have also become one of the major information sources of information for destination marketers, managers and planners that play important roles in destination policy and strategy development and the dissemination of information related to destination policies and strategies.

The very quick development of information technologies and the rapidly growing speed of information dissemination through the internet have tremendously revolutionized the tourism and hospitality industries. The internet started with the introduction of Web 1.0, and Web 2.0 has led to the emergence of social media environments, which have affected the connectivity of travelers and tourists around the world. Today, travelers gain their knowledge and evaluate destinations through utilizing several information sources, including traditional media, social media and peer-to-peer information sharing websites. Thus, what is being posted and reported in these traditional and non-traditional outlets plays an important role in travelers' destination selection and decision-making process. However, in recent years, the role played by traditional media outlets in the destination selection and decision-making process has been decreasing rapidly, while social media and peer-to-peer information sharing sites have been playing increasingly critical roles. However, the influences of social media and peer-to-peer information sharing sites on tourists' destination selection and decision-making process are very diverse and the components are very complex. Thus, destinations need to pay close attention to how and what type of information is being disseminated through a number of social media mediums and channels, and actively manage those channels in order to positively influence tourists' destination selection and decision-making processes.

It is important for destination managers and marketers to understand that information on social media flows not only from the official destination accounts but also from a large number of independent social media accounts, which serve as both producers and disseminators of information that can influence social media users' destination selection and decision-making processes. While those social media posts can have a great influence on travelers' attitudes and behaviors, they can also influence destination policies, strategies and future plans; since tourism is a highly sensitive and vulnerable industry, information disseminated on social media sites about destinations can significantly influence how social media user view them. Thus, it is critical for destination managers and marketers to pay close attention to the infor- 


\section{Handbook on tourism and social media}

mation shared by individuals on social media and peer-to-peer information sharing sites, in order to manage their effects on the destination and on potential visitors to the destination. Because of increasing interest among academic researchers in the increasingly important role of social media in the tourism and travel industry, a good number of studies have reviewed and investigated this relationship.

A quick review of the Web of Science records indicates that the number of papers which examined tourism and social media increased by more than 5000 per cent from 2009 to 2020 . According to very recent statistics from the Web of Science, in total 1702 articles have been found by using a search string ["tourism" AND "social media"]. The research growth rate and pattern is indicated in Figure 1.1, which very clearly indicates the increase in academic research, and hence the potential for young and new scholars interested in similar themes. Recent studies report that more than 67 percent of the information travelers use in destination selection and travel decision-making processes is gathered from virtual communities such as social media platforms and blogs. These trends clearly explain why destination managers, marketers, planners, researchers and decision-makers are becoming more interested in understanding the role of social media in tourism and hospitality. These trends can also explain why academia is also more interested in deciphering how in future managers and planners can develop more suitable social media skillsets.

Table 1.1, based on the records of the Web of Science, shows the authors who have written the most papers researching tourism and social media. We selected the authors who have written more than ten academic papers. The list indicates good collaboration opportunities for mid-stage researchers.

The Handbook on Tourism and Social Media carefully examines social media issues and challenges raised in the contemporary literature that are faced by destinations in their every-

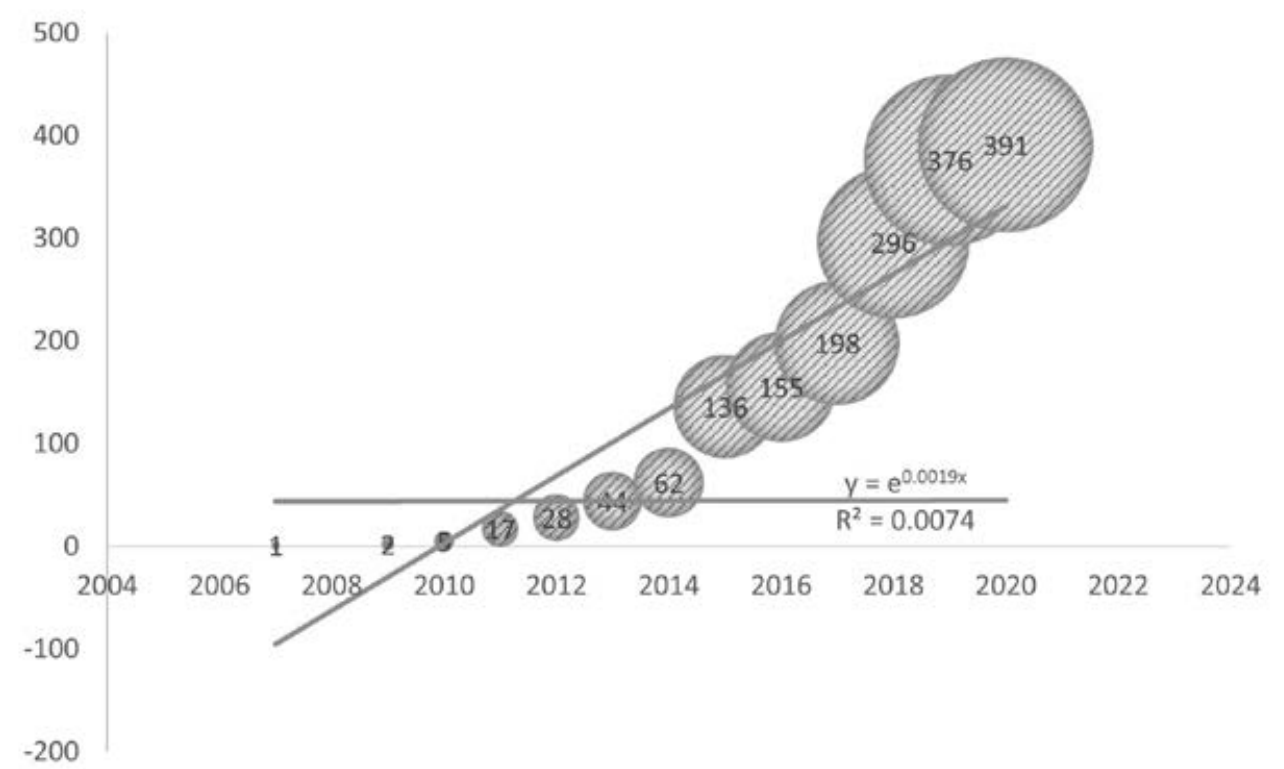

Figure 1.1 Increasing academic research on tourism and social media 
Table $1.1 \quad$ Authors contributing the most research on tourism and social media

\begin{tabular}{ll}
\hline Authors & Records \\
\hline Law, R. & 33 \\
Buhalis, D. & 21 \\
Gretzel, U. & 12 \\
Vu, H.Q. & 10 \\
Xiang, Z. & 10 \\
\hline
\end{tabular}

Source: Authors from Web of Science.

day operations. Defining key social media concepts and issues, and exploring the type of impacts they may have on the success of destinations, can enable us to set the stage for a better understanding of the relationships between social media and tourism. Furthermore, examining the current key trends and issues and then focusing on future trends within social media and destinations can provide critical insights for the successful development and implementation of destination social media marketing strategies and activities. The Handbook on Tourism and Social Media aims to examine key social media issues and challenges faced by destinations by carefully investigating destination social media practices and academic literature, in order to develop and propose strategies to address those key social media issues and challenges.

Our vision for this Handbook is to create an international platform for balanced academic social media research in tourism, with practical applications for destination managers and marketers, to foster synergetic interaction between academia and industry. This Handbook includes a collection of conceptual and empirical research chapters, practical case studies and review chapters, written by experts in the field, in order to develop a better understanding of the relationship between tourism and social media. The collection of topics presented in this Handbook represents an unprecedented scholarly attempt to cover a large number of both conceptual and practical topics. The contributors to this Handbook have provided in-depth coverage of each conceptual and practical topic, so that each chapter can serve as a trusted source of reference which can provide essential knowledge and references on the respective topic for academics and practitioners. It is our strong belief that the topics included in this Handbook will appeal to both researchers and practitioners. It is our sincere hope that those chapters will contribute to knowledge and theory of social media utilization in destination marketing and management as distinct, multifaceted fields, approached through the administrative disciplines, the liberal arts and the social sciences. Furthermore, this Handbook provides an outlet for innovative studies that can make a significant contribution to the understanding, practice and education of destination social media marketers and managers. We strongly believe that each chapter included in this Handbook will make a significant contribution to the dissemination of knowledge, while serving as a unique forum for both industry and academia.

The Handbook on Tourism and Social Media addresses cutting-edge social media issues in destination management and marketing. It includes 35 further chapters originating from leading social media scholars in the field. The book is divided into seven thematic parts, each theme exploring social media issues that are critical for destinations.

Part I provides an overview of consumer behaviour and social media and provides definitions of various concepts, and the role of social media in consumer behaviors. It also provides a critical review of factors that are likely to play important roles in consumer behavior and social media. 


\section{$4 \quad$ Handbook on tourism and social media}

Part II focuses on effects of social media on destinations and destination management/marketing organizations (DMOs). The chapters in this part show how DMOs have adopted social media in marketing and other management-related models. They also investigate destination image, brand image, and the visit intentions of tourists; and how online tourism communications affect image formation.

Part III examines social media marketing strategies, channels and formats. Social media marketing issues and challenges faced by destinations, and marketing strategies that are appropriate for various destinations, are discussed in these chapters.

Part IV investigates travel blogs, user-generated content, reviews, and electronic word-of-mouth (e-WOM). How user-generated content influences the decisions of other travelers is the main focus. The chapters adopt different methodologies: qualitative, quantitative, sentiment analytics, netnography, and others.

Part V examines the relationships between social media and decision-making by travelers. How social media stimulates the decisions of travelers, different phases, actions and motivations, are explored.

Part VI investigates the effects of social media on culinary and food tourism. Gastronomic events and further gastronomy-related aspects are explored. Chapter 31, specifically, talks about generation Z; while Chapter 32 reconnoiteres a case study on Singapore food tourism.

Part VII provides a critical overview of business performance-related challenges. It especially explores legal aspects and privacy-related issues. How social media supports the development of tourism, hospitality and events, and what Web 2.0 is, are addressed.

We, as editors of the Handbook on Tourism and Social Media, acknowledge the fact that we may have left out some critical topics and/or concepts. For the sake of simplicity and functionality we have focused on the topics that are most critical for social media researchers and tourism practitioners. Thus, the topics included in this Handbook do not provide complete or exhaustive coverage of the social media topics in tourism. For this, we apologize. Our goal is to simply gather together in one place the most critical social media topics in tourism, in order to create a credible source of information for today's and future researchers and practitioners to use as a point of departure for their research initiatives and business endeavors.

Contributors to this Handbook have worked countless hours to provide an in-depth coverage of each conceptual and practical topic, so that each chapter may serve as a trusted source of reference that can provide essential knowledge and references on the respective topic for academics and practitioners. We would like to express our sincere gratitude and thanks to all the contributors who graciously volunteered their time and effort to put this amazing Handbook together. 